\title{
Learning for Stewardship in the Anthropocene: A Study with Young Adolescents in the Wet Tropics
}

\author{
Marcia Thorne
}

James Cook University

etropic 14.1 (2015): 28-36. http://www.reefandleaf.com.au/etropic.html \& http://www.jcu.edu.au/etropic

\begin{abstract}
Enhancing student capacity to act for sustainability is recognised as an important strategy for reversing current patterns of environmental degradation. To achieve this, the emerging Australian Curriculum incorporates a sustainability cross-curriculum priority, designed to ensure students develop the necessary knowledge, skills, values and world views to contribute to more sustainable patterns of living. Stewardship has an important role to play in helping to develop sustainable patterns of living. However, it is not known to what extent or how the sustainability cross-curriculum priority includes stewardship.
\end{abstract}

This research investigates sustainability teaching and learning from an environmental stewardship perspective. Education based on environmental stewardship aims to develop an ethic of care for the natural and built world. Proponents of environmental stewardship argue that the approach is effective because it provides a foundation for the development of well-being, critical thinking and problem solving in tandem with the desire and confidence to act to maintain life supporting Earth Systems.

This research will apply an explanatory sequential mixed methods research design to map and review environmental stewardship in the Australian Curriculum's sustainability cross-curriculum priority and in Year 10 students and teachers in the Wet Tropics region of Australia. Research methods will include a document analysis of the Australian Curriculum's sustainability crosscurriculum priority; and survey and interviews to understand student and teacher subjective foundations of environmental stewardship and the expression of stewardship in school and life contexts. Subjective foundations include the existent aspirations, values and knowledge that guide student and teacher thinking and action for stewardship. Analysis and synthesis of this data, through a stewardship lens, will inform a stewardship pedagogical framework that will complement the sustainability curriculum.

Keywords: environmental stewardship, sustainability, ethic of care, care pedagogy, curriculum, Gen Z, Anthropocene.

\section{Introduction}

The current geological era has been named the Anthropocene by imminent academics in recognition of the unprecedented domination of Earth Systems by human activity, threatening the foundation of human civilisation (Garnaut, 2012; Rockström et al., 2009). The changes to Earth Systems (including climate and environment) are complex, uncertain and unprecedented, but predicted to alter all atmospheric structures, and marine and terrestrial biospheres (Steffen, 
Sanderson, \& Tyson, 2005); and disrupt social systems (Steffen et al., 2011) A 2009 assessment of the impact of human interference on Earth Systems provides convincing evidence. The study found that out of nine Earth Systems, three (climate change, species extinction and the nitrogen cycle) have already exceeded the boundary limit and four (ozone depletion, fresh water usage, ocean acidification and chemical pollution) are dangerously close (Rockström et al., 2009). The many challenges presented by the Anthropocene have resulted in a global call for planetary stewardship from eminent scientists and educators (Andrejewski, 2011; Arango, 2009; Barnett, Vaughn, Strauss, \& Cotter, 2011; Biermann et al., 2012; Bramston, Pretty, \& Zammit, 2011; Caldwell, Hayes, \& Long, 2010; Chapin, Carpenter, et al., 2010; Chapin, Young, et al., 2010; Rockström et al., 2009; Steffen et al., 2011; Tobias et al., 2010; Waterhouse, 2011). Some scholars argue that a lack of an adequate ethic of care lies at the core of the ecological crises of the Anthropocene (Eagles \& Demare, 1999; Kals, Schumacher, \& Montada, 1999; Kellert, 2012; Mortari, 2004). An ethic of care can be understood as "a moral code which advocates treating others, including the biotic community, in a loving, respectful and caring manner” (Litz, 2010, p. 10). Such qualities are important because they are critical to the support of the healthy functioning of life dependent Earth Systems (Chapin \& Olsson, 2009; Chapin, Young, et al., 2010; Folke, 2010; Rockström et al., 2009; Steffen et al., 2011). Such an ethic of care can be developed within an environmental stewardship understanding in environmental and sustainability curricula (Mortari, 2004). The focus of this research is to understand what expression planetary stewardship could have, and what expression it does have, in a secondary school education context in the Wet Tropics of Australia.

In this research education for environmental stewardship behaviour is defined as developing an ethic of care through i) developing respect, appreciation, affinity with and understanding of the natural world and its beauty, complexity and system interdependence; ii) recognition that humans (and all living creatures) depend on nature's complex life support systems and iii) understanding of the imperative for healthy Earth Systems. In education for environmental stewardship behaviour, these understandings and knowledge are foundational in the development of critical thinking and problem solving abilities, and foundational in the development of desire and confidence to act and maintain life supporting Earth Systems and the natural world (Hansla, Gamble, Juliusson, \& Gärling, 2008; Jickling \& Wals, 2012; Kevany, 2007; Martin \& Beatley, 1993; Næss \& Jickling, 2000; Satterfield, 2001; Schultz et al., 2005; Schultz \& Zelezny, 1998). The premise of this research is that the foci of education for sustainability and education for stewardship are divergent, and require separate consideration. The main difference is a crucial gap in meaning between sustainability, to maintain; and stewardship, to take care (Oxford on-line dictionary); and that this gap is reflected in pedagogy. This research also proposes that stewardship education is an important component of sustainability education.

\section{Literature Review}

Deeper penetration of the cultural context of the Anthropocene is required to understand its many inherent complexities. Here, a brief exploration of a portion of the relevant literature provides insight into the children of the Anthropocene, Gen Z; humanity's innate biophilic tendencies; the importance of educating to care; and how well-being fosters academic achievement.

The first generation of children of the Anthropocene are called Generation Z (Gen Z) and include those born between 1995 and 2009. Research forecasts that as adults Gen Z will be faced with unprecedented ecological crises. Comparative to previous generations, Gen $\mathrm{Z}$ has reduced experience of the outside world leading to use of the term 'the de-natured childhood' (Louv, 2005). Gen $Z$ live and plays indoors, with an average of fifty-two hours per week spent on electronic media compared to less than one hour outside (Kellert, 2012). Gen Z also display eco- 
phobia resulting from their inside life style disconnecting them from the outside natural world, but 'digital connecting' them globally with endangered animals and ecosystems (Sobel, 1996, 2005; Strife, 2010, 2012).

Survey data collected in 47 Central Switzerland high schools, as part of a meta-analysis of teacher education, was analysed to understand what 15 and 16 year olds thought about environmental issues (Zeyer \& Roth, 2013). To obtain deeper understanding, three classes of 20 to 25 students from different schools, were interviewed on videotape; and after analysis of this data, 12 students were selected for in-depth video interviews (Zeyer \& Roth, 2013). Analysis of interview discourse revealed two main interpretive repertoires and four second order repertoires. Interpretive repertoires are the building blocks that speakers use to develop opinions and accounts of events. To summarise Zeyer and Roth's study, student repertoires were based on common knowledge, what Zeyer and Roth termed folk science and folk psychology, as opposed to scientific understanding and theory; and agency tensions, tensions about the power to act and change an individuals' social and natural worlds.

After further analysis of this data, Zeyer and Kelsey suggest a culture clash exists between Gen Z (the students) and the environmental education curriculum (2013). Zeyer and Kelsey attributed the culture clash to non-alignment of student worldviews with the environmental education curriculum, naming student worldviews, 'the post-ecologism life-world culture of western youth'. In a post-ecologism worldview, individuals understand on face value that the status quo is unsustainable, but put forward many reservations and doubts that sustainable change will occur (Zeyer \& Kelsey, 2013). These individuals display apathy about their ability to influence environmental conditions; offer a rhetoric of othering - 'the others' lacked care for environmental issues; have a belief that technology will fix environmental problems; are committed to consumerism; and dislike nongovernmental actors and green politics (Zeyer \& Kelsey, 2013). Understanding how to match pedagogy to Gen Z, in the context of the ecological challenges presented by the Anthropocene, is very important. The eco challenges of the Anthropocene and the eco preparedness of Gen $\mathrm{Z}$ present a serious dichotomy.

The term biophilia used by Wilson and Kellert to describe humanity's connection with the natural world, best aligns with how environmental stewardship is used in this research (2012). E. O. Wilson and Stephen Kellert describe biophilia as "the inherent inclination to affiliate with the natural world, instrumental to people's physical and mental health, productivity and well-being” (Kellert, 2012, p. xii) and Kellert continues, humans are born with an affinity for the natural world, but it is an adaptive process which must be cultivated and learned. Kellert states that distortions in biophilic values in modern times, has led to widespread environmental degradation and increasing alienation from nature and "a fundamental shift in human consciousness and the emergence of a new ethic will be required to resolve our current linked environmental and social crises” (Kellert, 2012, p. xiii, italics added).

Educating to care and the concept of care in pedagogy is centuries old and dates to the ancient Greeks and is found in the works of Plato and Socrates (Mortari, 2004). Essential requirements to educate for and develop a care ethic include teacher modelling and affording students' opportunities to care (Noddings, 2010). Development of an ethical disposition to care is possible and requires a reconstruction of the 'western cultural framework' to develop through practice, a new ecological nature care ethic (Mortari, 2004). Development of care ethics and environmental stewardship behaviour is imperative as the lack of an adequate ethic to care lies at the core of the ecological crises (Mortari, 2004). 
Two examples of educating to care have occurred in the last 20 years via two world mass media 'education events' resulting in transformative stewardship behaviour (Kellert, 2012). Education about the near extinction of whales motivated both public and political will to enact changes in law and policy resulting in an international 'Save the Whales' effort. Secondly, a substantial shift in attitudes and opinions to wetlands in the United States (previously referred to as swamps and routinely exploited), resulted in the Bush administration declaring a national policy of 'no net loss of wetlands', as nearly half of US wetlands, (approximately 100 million acres) had been lost in 200 years of European settlement (Kellert, 2012).

Environmental stewardship fosters well-being which includes happiness, a sense of fate control and community capacity (Kofinas \& Chapin, 2009). Further, the relationship between wellbeing, livelihood, and natural and social capital define the prospects for long term sustainability (Janssen and Scheffer, 2005 cited in Kofinas \& Chapin, 2009). Well-being depends on the acquisition of basic psychological and safety needs which include ecosystem services (Kofinas \& Chapin, 2009),

Academic study when integrated with place-based environmental education develops well-being and provides the capacity for higher order thinking to facilitate problem solving and improved academic achievement (Emekauwa, 2004; Lieberman \& Hoody, 1998; Powers, 2004; SEER, 2000; Sobel, 2005; cited in Litz, 2010). Development of well-being, to summarise these extensive studies, promotes scholastic performance.

This research proposes that education for higher order thinking is required for effective environmental stewardship (and vice versa) to mitigate the eco crises of the Anthropocene, and to build capacity in students for the uncertainties and challenges that will undoubtedly face them as tomorrow's adults. In agreement, Kellert proposes a transformative ethic of care or stewardship is required, and to achieve this human physical, mental, spiritual and intellectual tendencies must be nurtured and developed through adequate learning and experience to become fully functional (Kellert, 2012). Further, humanity can only achieve lives of meaning and satisfaction by living in right relation to the world beyond themselves and "If people lack sufficient knowledge, love and faith in the value of nature, they will not be motivated to embrace their experiential dependence on the natural world" (Kellert and Speth, 2009, cited in Kellert, 2012, p. 188) and in turn care for the natural world.

Self-efficacy is the belief an individual has in their capacity to undertake an action. Tabernero and Hernandez found that an individual's belief in their capacity to undertake environmentally responsible behaviour was directly related to intrinsic motivation and intrinsic reward, perpetuating a behaviour, motivation and reward cycle (2011). This cycle reinforces Kellert and Speth's notion of having capacity to embrace humanity's experiential dependence on the natural world and to think and act sustainably.

\section{Methodology}

This research applies a mixed methods approach through an explanatory sequential design (Creswell, 2012) to map and review environmental stewardship in five state high schools in the Wet Tropics. An explanatory sequential design first collects quantitative data to explain the research problem in general terms then, uses qualitative data to refine, deepen and, if necessary, refocus the research problem. The explanatory sequential research design is well suited to examine multilevel complex topics, in this instance, environmental stewardship (Tashakkori \& Teddie, 1998, cited in Creswell, 2012). 
Briefly, this research is focused on understanding if and how, an ethic of care for the environment is being developed in formal schooling; through analysis of curriculum and working with Year 10 students and teachers in state high schools in the Wet Tropics. The overarching research question is:

What is the relationship between environmental stewardship, Year 10 students and their teachers, and the Australian Curriculum's sustainability cross-curriculum priority, within the Wet Tropics region of Australia?

The following sub-questions are framed to assist answering this question:

a) To what extent and how is environmental stewardship represented in the Australian Curriculum's sustainability cross-curriculum priority?

b) How is environmental stewardship, as represented in the Australian Curriculum's sustainability cross-curriculum priority, enacted in the school context?

c) What environmental stewardship aspirations, values, knowledge, beliefs and action capacities do Year 10 students and their teachers have?

d) How are the environmental stewardship aspirations, values, knowledge, beliefs and action capacities of the Year 10 students and teachers realised or how do they play out in reality?

The research format involves three phases - document analysis, on-line surveys and interviews. Document or content analysis, is on-going through a sustainability and stewardship lens, of historical documents leading to development of the Australian Curriculum (AC), of the Australian Curriculum Sustainability Cross Curriculum Priority (AC SCCP) and of Year 10 subjects in C2C. C2C is an acronym for Curriculum to Classroom, which is Education Queensland's adaption of the AC for Queensland schools. But firstly, analysis of lead historical education documents produced by the Australian Government will set the context and priority for stewardship and sustainability education in Australia. These documents include, but are not limited to, the First National Action Plan in 2000; Education for a Sustainable Future - a national statement on environmental education developed in 2005; the second National Action Plan Living Sustainably: The Australian Government’s National Action Plan for Education for Sustainability from 2009, and The Sustainability Curriculum Framework, A Guide for Curriculum Developers and Policy Makers from 2010.

The second stage of the research format was on-line surveys with students and teachers focused on understanding the relationship between basic values, attitudes to the environment, and knowledge and actions towards the environment. The on-line survey has 3 sections. Section 1 of the survey follows Schwartz (2009) Values Theory, which is based on 10 motivationally distinct values, common to all cultures. Values are beliefs tied to emotion, are motivational, transcend specific actions and situations, serve as standards, and are ordered by importance, and the relative importance of multiple values guides actions (Schwartz, 2012). Values are guiding principles in people's lives. Section 2 is based on Milfont and Duckitt's Environmental Attitude Index (EAI), (2010). Environmental attitudes have cognitive, affective and behavioural components and are multidimensional and hierarchical. The index is based on 12 scales. Section 3 was designed by the researcher to understand what knowledge participants have about environmental issues, where they obtain their knowledge, and what environmental actions they take.

The third stage of the research format involved focus group conversations with four to six Year 10 students from each school and conversational interviews with Year 10 teachers which 
provided deeper understandings of value prioritisation and how environmental attitudes become enacted. Conversation questions were informed by responses to on-line surveys.

\section{Preliminary Findings}

Data collation from document analysis is on-going. Initial findings suggest that between the years 2000 and 2005, stewardship was considered an important education goal in Australia, but faded in priority as the United Nations Decade of Education for Sustainable Development became entrenched in Australian education focus.

To date, ninety percent of data has been collected. Statistical analysis of on-line survey data will begin later this month. Transcription of conversations with students and teachers, will also begin later this month, to allow for coding and theming of content.

However, initial findings suggest that environmental stewardship education is not a priority and is not occurring in formal schooling in Year 10, and that sustainability education has a low priority and occurs sporadically. Data collected to date suggests that sustainability education is subject driven as opposed to whole school culture, is hindered by time constraints and fraught with difficulties. Difficulties include de-prioritisation of subject electives where stewardship and/or sustainability may be taught; an emphasis on theoretical application of sustainability principles over practical learning experiences; an inability, due to a lack of resources, to engage in practical stewardship and/or sustainability learning; an emphasis on indoor, formal literacy and numeracy teaching and learning, without consideration of the research that well-being from immersion in the natural environment leads to enhanced scholastic performance; and curriculum demands for academic outcomes at the exclusion of all else.

Initial analysis of student focus group conversations reveal a lack of student knowledge and factual information sources about the ecological challenges of the Anthropocene. Students also expressed concerns akin to a 'festering' fear, that something is very wrong without knowing what it is; impotence about their own personal role and how effective that role will be in response to any environmental challenges; apathy, that it's all too hard and why bother; pressing social identity issues, friendship groups and the pursuit of fun are more important and tangible; and it's too late to teach 15 year olds how to care for the environment, as their brains have become 'hardwired'; and that learning to care for the environment should happen at a younger age, at primary school.

In all focus group conversations, the students made some interesting comments about their friends and peers environmental attitudes and behaviours. Overall, the participant students were considered high achievers with a caring (as determined by their teacher) attitude towards the environment. The sentiments expressed in the previous paragraph were largely their values, attitudes and actions. The students also expressed how concerned they were that the majority of 15 year olds had no concept of care for the environment. Students summarised their class mates' environmental knowledge and attitude as ‘most kids don’t know and don’t care'.

\section{Conclusion}

This research proposes to understand the relationship between environmental stewardship, and formal teaching and learning in Year 10 state schools in the Wet Tropics region of Australia. This research involves document analysis, through a stewardship lens, of Australian government lead educational documents prior to development and implementation of the Australian 
Curriculum, analysis of the Australian Curriculum Sustainability Cross Curriculum Priority, and of Year 10 subjects in C2C - Curriculum 2 Classroom. On-line surveys with Year 10 students and their teachers explored the relationship between values, environmental attitudes, action and knowledge; and survey responses informed focus-group conversations with students and conversational interviews with teachers, to gain deeper understandings.

Data analysis is on-going. It is expected that outcomes will be presented in the candidate's thesis in October 2015. Preliminary findings suggest that stewardship education is not occurring, that student knowledge of, and concern for environmental challenges is limited. This appears in direct contrast to the stated goal of the Australian Curriculum to "prepare[s] Australia's next generation for the future” (ACARA, 2014).

\section{Works Cited}

ACARA. (2014). Australian Curriculum F-10 Overview. from http://www.australiancurriculum.edu.au/curriculum/overview

Andrejewski, R. G. (2011). Nature connection, outdoor play, and environmental stewardship in residential environmental education. (Dissertation/Thesis). Retrieved from http://jcu.summon.serialssolutions.com/link/0/eLvHCXMwY2BQMEwzTDEyTbUAtlRB ySfRwsQ42QSYUpJSLJMsU8AXwSB2xyGV5m6iDHJuriHOHrqwUjEJScnHlgBmYJOYbMwNBRj4E0ELfzOKwFvEEvhO3R_ctv-9V4fe79L_lryWY_AGYsJaM

Arango, J. D. (2009). Teaching Environmental Stewardship. Children's Technology and Engineering 14(2), 7.

Barnett, M., Vaughn, M. H., Strauss, E., \& Cotter, L. (2011). Urban Environmental Education: Leveraging Technology and Ecology to Engage Students in Studying the Environment. International Research in Geographical and Environmental Education, 20(3), 199-214.

Biermann, F., Folke, C., Gupta, A., Gupta, J., Haas, P. M., Jordan, A., . . Clapp, J. (2012). Navigating the Anthropocene: Improving Earth System Governance. SCIENCE, 335(6074), 1306-1307. doi: 10.1126/science.1217255

Bramston, P., Pretty, G. H., \& Zammit, C. (2011). Assessing Environmental Stewardship Motivation. Environment and Behavior, 43(6), 776-788. doi: 10.1177/0013916510382875

Caldwell, C., Hayes, L. A., \& Long, D. T. (2010). Leadership, Trustworthiness, and Ethical Stewardship. Journal of Business Ethics, 96(4), 497-512. doi: 10.1007/s10551-010-0489$\mathrm{y}$

Chapin, F. S., Carpenter, S., Kofinas, G., Folke, C., Abel, N., Clark, W. C., . . . Young, O. R. (2010). Ecosystem stewardship: sustainability strategies for a rapidly changing planet. Trends in Ecology \& Evolution, 25(4), 241-249.

Chapin, F. S., \& Olsson, P. (2009). Transformations in Ecosystem Stewardship (pp. 103-125). New York, NY: Springer New York.

Chapin, F. S., Young, O. R., Berkes, F., Biggs, R., Grove, J. M., Naylor, R. L., . . Stockholm Resilience, C. (2010). Ecosystem stewardship: sustainability strategies for a rapidly changing planet. Trends in Ecology \& Evolution, 25(4), 241-249. doi: 10.1016/j.tree.2009.10.008

Creswell, J. (2012). Educaitonal Research Planning, Conducting, and Evaluating Quantitative and Qualitative Research (4th ed.). Boston: Pearson.

Eagles, P. F., \& Demare, R. (1999). Factors influencing children's environmental attitudes. The Journal of Environmental Education, 30(4), 33-37. 
Folke, C. (2010). How resilient are ecosystems to global environmental change? Sustainability Science, 5(2), 151-154. doi: 10.1007/s11625-010-0109-x

Garnaut, R. (2012). Can humanity manage the Anthropocene?: the challenge of climate change Paper presented at the 'Anthropocene Humanities' 2012 Annual Meeting of the Consortium of Humanities Centers and Institutes, Australian National University, Canberra.

Hansla, A., Gamble, A., Juliusson, A., \& Gärling, T. (2008). The relationships between awareness of consequences, environmental concern, and value orientations. Journal of environmental psychology, 28(1), 1-9.

Jickling, B., \& Wals, A. (2012). Probing Normative Research in Environmental Education. International Handbook of Research on Environmental Education, 74.

Kals, E., Schumacher, D., \& Montada, L. (1999). Emotional affinity toward nature as a motivational basis to protect nature. Environment and Behavior, 31(2), 178-202.

Kellert, S. R. (2012). Birthright - People and nature in the modern world. New Haven, US: Yale University Press.

Kevany, K. D. (2007). Building the requisite capacity for stewardship and sustainable development. International Journal of Sustainability in Higher Education, 8(2), 107-122.

Kofinas, G. P., \& Chapin, F. S. (2009). Sustaining Livelihoods and Human Well-Being during Social-Ecological

Change. Principles of Ecosystem Stewardship, 55-75. doi: 10.1007/978-0-387-73033-2

Litz, K. (2010). Inspiring Environmental Stewardship: Developing a sense of place, critical thinking skills, and ecoliteracy to establish an environmental ethic of care. (Master of Arts), Prescott College.

Louv, R. (2005). The Criminalization of Natural Play [Last Child in the Woods]. Natural Life(Journal Article), 16.

Martin, E., \& Beatley, T. (1993). Our relationship with the earth: Environmental ethics in planning education. Journal of Planning Education and Research, 12(2), 117-126.

Milfont, T. L., \& Duckitt, J. (2010). The environmental attitudes inventory: A valid and reliable measure to assess the structure of environmental attitudes. Journal of environmental psychology, 30(1), 80-94.

Mortari, L. (2004). Educating to care. Canadian Journal of Environmental Education (CJEE), 9(1), pp. 109-122.

Næss, A., \& Jickling, B. (2000). Deep ecology and education: A conversation with Arne Naess. Canadian Journal of Environmental Education (CJEE), 5(1), pp. 48-62.

Noddings, N. (2010). Moral Education in an Age of Globalization. Educational Philosophy and Theory, 42(4), 390-396. doi: 10.1111/j.1469-5812.2008.00487.x

Rockström, J., Schellnhuber, H., Nykvist, B., de Wit, C. A., Hughes, T., van der Leeuw, S., . . . Teknik- och, v. (2009). Planetary Boundaries: Exploring the Safe Operating Space for Humanity. Ecology \& society(Journal Article).

Satterfield, T. (2001). In search of value literacy: suggestions for the elicitation of environmental values. Environmental Values, 10(3), 331-359.

Schultz, P., Gouveia, V., Cameron, L., Tankha, G., Schmuck, P., \& Franěk, M. (2005). Values and their relationship to environmental concern and conservation behavior. Journal of cross-cultural psychology, 36(4), 457-475.

Schultz, P., \& Zelezny, L. (1998). Values and Proenvironmental Behavior A Five-Country Survey. Journal of cross-cultural psychology, 29(4), 540-558.

Schwartz, S. H. (2012). An overview of the Schwartz theory of basic values. Online Readings in Psychology and Culture, 2(1), 11.

Sobel, D. (1996) Beyond Ecophobia. Great Barrington, USA: The Orion Society.

Sobel, D. (2005). Place-based Education. Great Barrington, USA: The Orion Society. 
Steffen, W., Gordon, L., Molina, M., Ramanathan, V., Rockström, J., Scheffer, M., .. . Folke, C. (2011). The Anthropocene: From Global Change to Planetary Stewardship. Ambio, 40(7), 739-761. doi: 10.1007/s13280-011-0185-x

Steffen, W., Sanderson, A., \& Tyson, P. (2005). The Anthropocene Era: How Humans are Changing the Earth System In Global Change adn the Earth System - A Planet Under Pressure (pp. 81-141).

Strife, S. (2010). Reflecting on Environmental Education: Where Is Our Place in the Green Movement? Journal of Environmental Education, 41(3), 179-191. doi: 10.1080/00958960903295233

Strife, S. (2012). Children's Environmental Concerns: Expressing Ecophobia. The Journal of Environmental Education, 43(1), 37-54.

Tabernero, C., \& Hernández, B. (2011). Self-efficacy and intrinsic motivation guiding environmental behavior. Environment and Behavior, 43(5), 658-675.

Tobias, P., F, S., Gary, P., Carl, C., Kofinas, \& Folke. (2010). Principles of Ecosystem Stewardship: Resilience-Based Natural Resource Management in a Changing World. Environmental Conservation, 37(2), 223. doi: 10.1017/s0376892910000470

Waterhouse, J. (2011). Finding balance between human need and global stewardship. Conservation biology : the journal of the Society for Conservation Biology, 25(6), 10871090. doi: 10.1111/j.1523-1739.2011.01764.x

Zeyer, A., \& Kelsey, E. (2013). Environmental Education in a Cultural Context. In R. B. Stevenson, M. Brody, J. Dillon \& A. E. J. Wals (Eds.), International Handbook of Research on Environmental Education. New York: Routledge.

Zeyer, A., \& Roth, W.-M. (2013). Post-ecological discourse in the making. Public understanding of science, 22(1), 33-48. 